\title{
Perspectivas de uma Educação Inclusiva na rede estadual de ensino de Breves,
} arquipélago do Marajó, Pará

\author{
Perspectives of Inclusive Education in the state school system of Breves, archipelago of Marajó, \\ Pará
}

Perspectivas de la Educación Inclusiva en la red educativa estatal de Breves, archipiélago de Marajó, Pará

Essia de Paula Romão-Torres ORCID: https://orcid.org/0000-0002-1578-2258 Instituto Federal de Educação, Ciência e Tecnologia de Sergipe, Brasil E-mail: essia.romao@ifs.edu.br

Julia Siqueira Moreau

ORCID: https://orcid.org/0000-0002-0107-9262 Instituto Federal de Educação, Ciência e Tecnologia do Pará, Brasil E-mail: julia.moreau@ifpa.edu.br

Gabrielly Costa Lino ORCID: https://orcid.org/0000-0002-0408-5545 Instituto Federal de Educação, Ciência e Tecnologia do Pará, Brasil E-mail: 2702gabrielly@gmail.com

Kevin Washington Azevedo da Cruz ORCID: https://orcid.org/0000-0002-7087-8105 Instituto Federal de Educação, Ciência e Tecnologia do Pará, Brasil E-mail: washingtonkevin703@gmail.com

\begin{abstract}
Resumo
A educação inclusiva tem se constituído como um avanço na formação de alunos com necessidades educativas especiais, diferenciando-se do modelo segregado. No Pará, tem se desenvolvido no ensino regular com apoio especializado, além das instituições específicas. Em Breves, no Marajó, atividades nessa perspectiva iniciaram na década de 1980, através de cursos de capacitação, um processo gradativo e excludente, onde a participação era restrita apenas àqueles considerados aptos a desenvolver habilidades e competência em turmas de ensino regular. Neste sentido, objetivou-se conhecer a atual conjuntura da educação inclusiva no ensino médio da rede estadual urbana de Breves. A metodologia correspondeu na aplicação de questionários com entrevistas semiestruturadas a funcionários das escolas alvo deste estudo. Tem-se como resultados a constituição e discussão dos perfis Histórico escolar; Educação inclusiva da escola; Perfil dos alunos PcD's e o Perfil de acessibilidade escolar. É conclusivo a necessidade de uma acessibilidade pedagógica e estrutural nas escolas, onde faça-se com que a inclusão não se limite a atendimentos educacionais especializados e espaços acessíveis, mas uma abordagem que promova uma inclusão holística, de documentos institucionais a práticas pedagógicas e sociais.
\end{abstract}

Palavras-chave: Educação; Ensino; Inclusão; PcD; Amazônia.

\begin{abstract}
Inclusive education has been constituted as an advance in the training of students with special educational needs, differentiating from the segregated model. In Pará, it has developed in regular education with specialized support, in addition to specific institutions. In Breves, in Marajó, activities in this perspective began in the 1980s, through training courses, a gradual and exclusive process, where participation was restricted only to those considered able to develop skills and competence in classes of regular education. In this sense, the objective was to know the current conjuncture of inclusive education in secondary education in the urban state network of Breves. The methodology corresponded to the application of questionnaires with semi-structured interviews to employees of the schools targeted by this study. The results are the constitution and discussion of the school history profiles; Inclusive school education; Profile of students PwD's and the Profile of school accessibility. The need for pedagogical and structural accessibility in schools is conclusive, where inclusion is not limited to specialized educational services and accessible spaces, but an approach that promotes holistic inclusion, from institutional documents to pedagogical and social practices.
\end{abstract}

Keywords: Education; Teaching; Inclusion; PcD; Amazon. 


\begin{abstract}
Resumen
La educación inclusiva se ha constituido como un avance en la formación de estudiantes con necesidades educativas especiales, diferenciándose del modelo segregado. En Pará, se ha desarrollado en educación regular con apoyo especializado, además de instituciones específicas. En Breves, en Marajó, las actividades en esta perspectiva se iniciaron en la década de los ochenta, a través de cursos de capacitación, un proceso gradual y exclusivo, donde la participación se restringió solo a aquellos considerados capaces de desarrollar habilidades y competencias en las clases de educación regular. En este sentido, el objetivo fue conocer la coyuntura actual de la educación inclusiva en la educación secundaria en la red urbana estatal de Breves. La metodología correspondió a la aplicación de cuestionarios con entrevistas semiestructuradas a los empleados de las escuelas objetivo de este estudio. Los resultados son la constitución y discusión de los perfiles de historia escolar; Educación escolar inclusiva; Perfil de los alumnos de PwD y perfil de accesibilidad escolar. Concluimos la necesidad de una accesibilidad pedagógica y estructural en las escuelas, donde la inclusión no se limite a servicios educativos especializados y espacios accesibles, sino un enfoque que promueva la inclusión holística, desde los documentos institucionales hasta las prácticas pedagógicas y sociales.
\end{abstract}

Palabras clave: Educación; Enseñanza; Inclusión; PcD; Amazonas.

\title{
1. Introdução
}

A educação inclusiva tem se constituído como um avanço na formação de alunos com necessidades educativas especiais, sobressaindo a um modelo de atendimento segregado, paralelo ao ensino regular (Glat \& Fernandes, 2005), que tem a postura de isolar tais alunos no processo educacional. Desta forma, a inclusão ocorre através de um procedimento de reformulação sistêmica, desenvolvendo estratégias para um ambiente igualitário e participativo, em uma escola que supera barreiras (Hehir et. al., 2016).

Neste contexto, a educação inclusiva tem recebido mais atenção, a partir de meados do século XX, através das declarações internacionais ${ }^{1}$ e leis nacionais ${ }^{2}$, quem tem desenvolvido um papel crucial na transformação e promoção das políticas públicas educacionais. Contudo, é importante destacar que no Brasil, a tentativa de idealização de uma educação mais inclusiva ocorreu de formas distintas, incluindo ações de segregação e, inclusive rejeição, até chegar à institucionalização desta nova forma de ensino (Garcia \& Favaro, 2020). Assim, o fortalecimento da matriz política e científica da Educação Especial passou a ser a integração de deficientes na sociedade, com um pensar do espaço social através redemocratização do país (Glat \& Fernandes, 2005).

No estado do Pará, a educação inclusiva tem se desenvolvido no ensino regular com apoio especializado, além da atuação de instituições específicas para atender estas demandas (Costa, 2006). Já no arquipélago do Marajó, especificamente no município de Breves, as atividades voltadas na perspectiva da educação inclusiva tiveram início na década de 1980, através da atuação da $13^{\text {a }}$ Unidade Regional de Ensino de Breves - SEDUC-PA, promovendo cursos de capacitação por intermédio do Departamento de Educação Especial - DESS (Melo, 2015). Desta forma, a implantação da educação especial no município desenvolve-se num processo gradativo e excludente, onde a participação era restrita apenas àqueles considerados aptos a desenvolver habilidades e competência em turmas de ensino regular (PME, 2015).

No entanto, a educação inclusiva promove benefícios sociais e acadêmicos a alunos com e sem necessidades especiais, por fomentar o desenvolvimento socioemocional, reduzir preconceitos e valorizar a diversidade (Hehir et. al., (2016). Por isso, presente pesquisa é necessária, a fim de preencher lacunas acerca dos desafios e perspectivas da Educação Inclusiva no Marajó, através da atuação das escolas estaduais urbanas do município de Breves. Neste sentido objetivou conhecer a atual conjuntura da educação inclusiva no ensino médio da rede estadual urbana de Breves, Arquipélago do Marajó,

\footnotetext{
${ }^{1}$ Declaração de Sulamanca, que reforça a necessidade de crianças e jovens portadores de necessidades educativas terem acesso a escolas regulares, como um meio de combater atitudes discriminatórias (UNESCO, 1994); Convenção das Nações Unidas sobre os Direitos das Pessoas com Deficiência, que teve como principal proposta a discussão internacional quanto aos efetivos os direitos das pessoas com deficiência, reforçando o acesso ao ensino regular (FERREIRA; OLIVEIRA, 2007).

${ }^{2}$ Lei de Diretrizes e Bases da Educação Nacional (9394/96), que trata a educação especial como uma modalidade gratuita oferecida preferencialmente na rede regular de ensino aos educandos portadores de necessidades especiais (BRASIL, 1996); Plano Nacional de Educação 10.172/01, onde estabelece objetivos e metas para a educação especial, fomenta a implantação de programas educacionais e a formação continuada dos professores (BRASIL, 2001).
} 
estado do Pará

\section{Metodologia}

\section{1 Área de estudo}

A mesorregião do Marajó, está localizada no estado do Pará e compreende municípios fluviais, que se localizam integralmente no arquipélago e municípios continentais (Brasil, 2007), ligados pelos rios e furos, com características ambientais, socioeconômicas e culturais semelhantes (Figura 1).

Figura 1: Localização do município de Breves no arquipélago do Marajó.

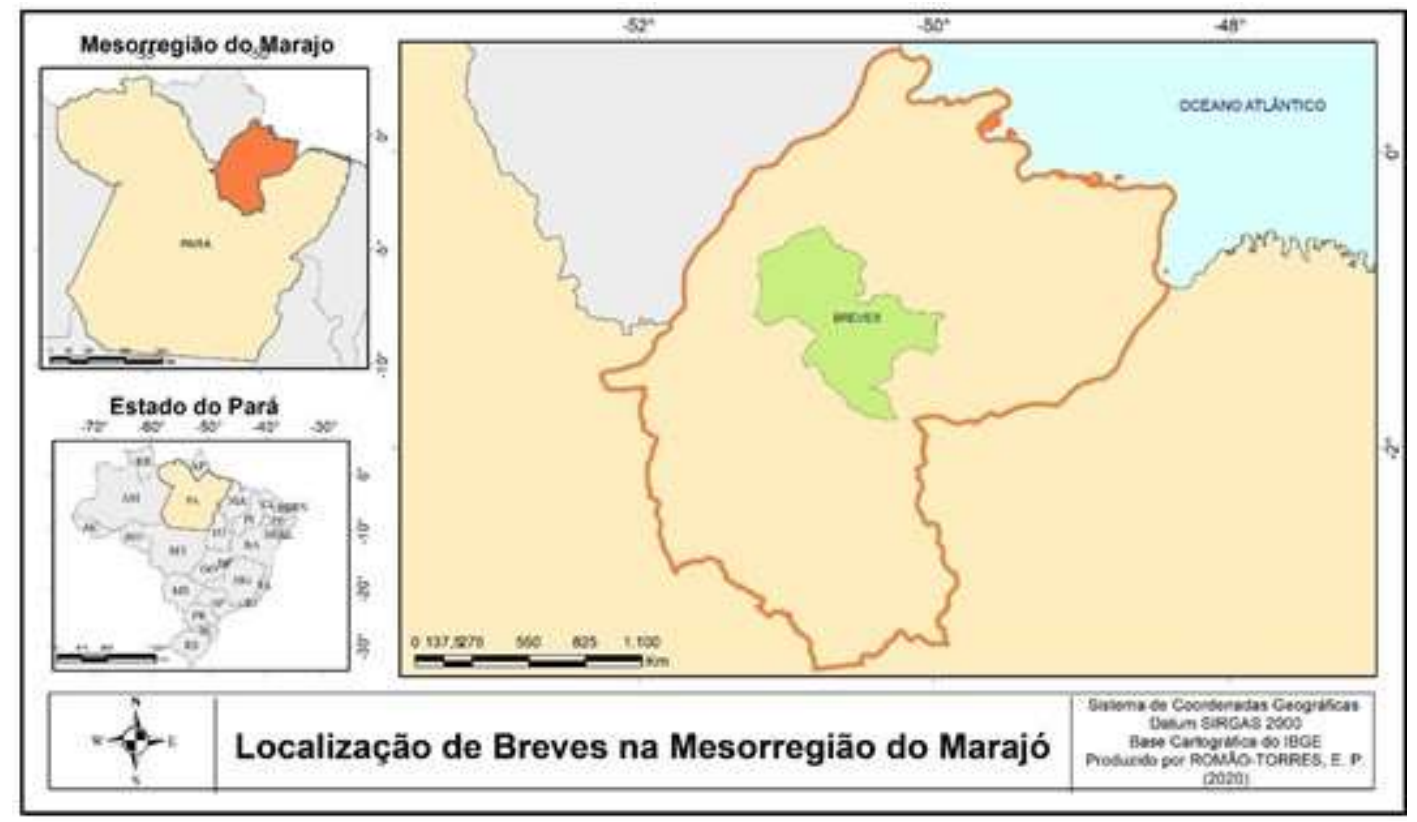

Fonte: Romão-Torres (2020).

\subsection{Tipo de Pesquisa}

Esta pesquisa se enquadra em duas abordagens analíticas, a saber, quantitativa e qualitativa. A primeira, por buscar descrever e caracterizar os alunos portadores de necessidades especiais presentes nas escolas alvos deste estudo, na perspectiva abordada por Valpato (2015). E qualitativa, pelo ensaio em compreender as realidades, dificuldades e atitudes dos sujeitos envolvidos (Ferreira, 2015).

\subsection{Público-alvo}

O público-alvo deste trabalho foram escolas da rede estadual de ensino localizadas na sede urbana de Breves-PA, por ofertarem o ensino médio no município, por ser um nível de escolaridade oferecido também pelo IFPA-Campus Breves, buscou-se conhecer tal. Nesta abordagem a pesquisa foi desenvolvida nas instituições: I) Escola Estadual de Ensino Médio Professora Maria Câmara Paes (MCP); II) Escola Estadual de Ensino Médio Professora Maria Elizete Fona Nunes; III) Escola Estadual de Ensino Médio Professor Gerson Peres e IV) Escola Estadual de Ensino Fundamental e Médio Santo Agostinho.

\subsection{Coleta de dados}

Para a coleta de dados foi utilizado como instrumento de pesquisa a aplicação de questionários, com questões abertas e fechadas, através de entrevista semiestruturada, de acordo com a necessidade dos diferentes públicos-alvo. A utilização destes instrumentos visou, sobretudo, traçar um caminho sistemático na busca de entender a problemática estudada, através de 
questionamentos acerca dos desafios e perspectivas da vida cotidiana escolar, sendo este, pressupostos da pesquisa científica (Minayo, 2000).

\subsection{Tabulação dos dados}

Nesta etapa metodológica foi realizada a transcrição e sistematização dos dados coletados, juntamente com a produção gráfica dos resultados, na busca de discuti-los e analisá-los, para assim, responder aos questionamentos levantados. Sendo este, um procedimento de grande importância na produção científica, pelo esforço que exige na interpretação e compreensão dos resultados, trazendo representatividade acadêmica às interpretações geradas (Tozoni-Reis, 2009).

\subsection{Plano de atividades}

Para atender ao proposto por esta pesquisa, foram realizados os procedimentos metodológicos representados no fluxograma abaixo (Figura 2). O plano de atividade foi estruturado em três (03) etapas correspondentes ao I) Levantamento bibliográfico; II) Desenvolvimento, aplicação e estudos do instrumento de pesquisa e III) visitas de planejamento e entrevistas as escolas.

Figura 2: Procedimentos metodológicos para desenvolvimento da pesquisa.

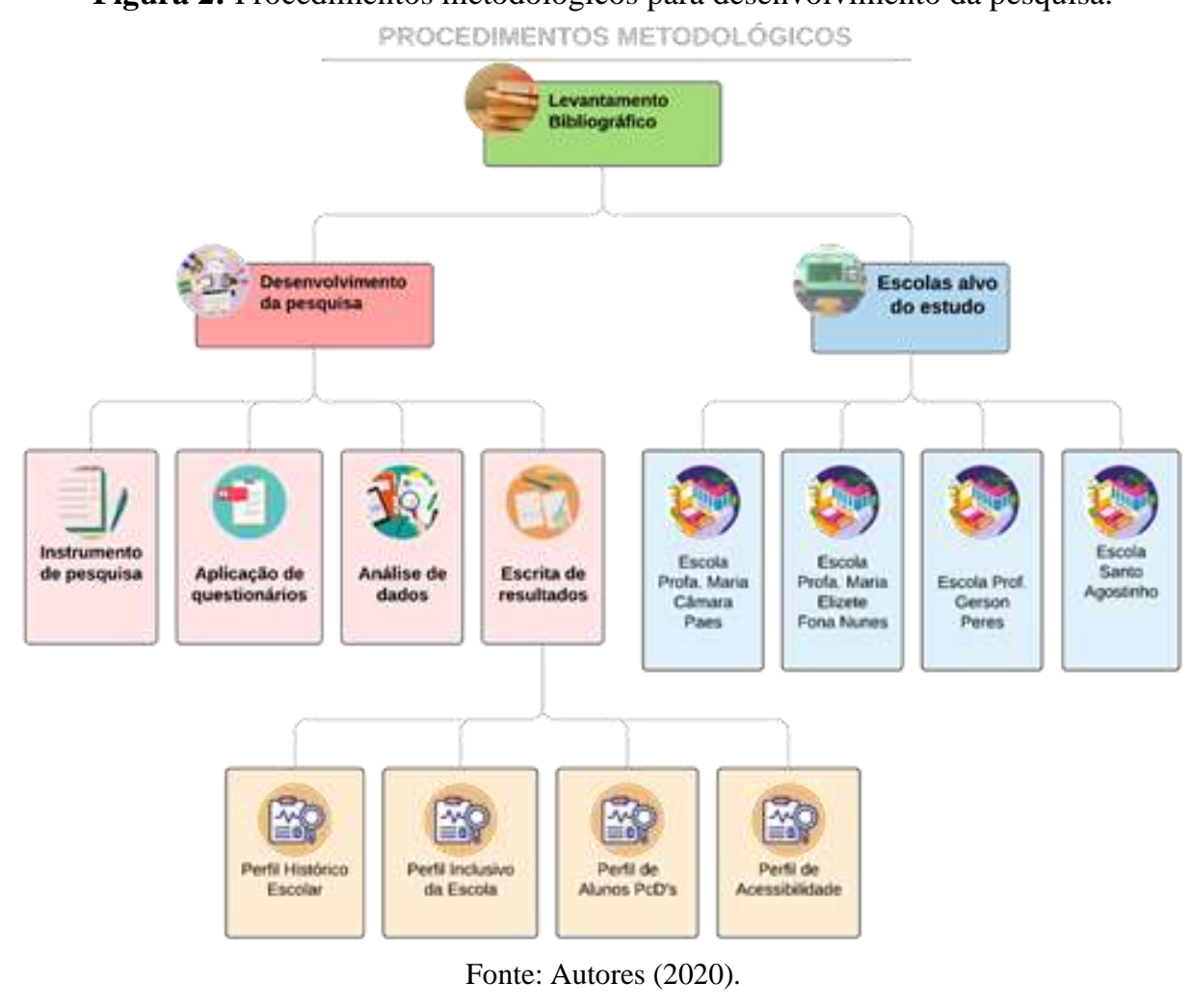

\section{Resultados e Discussão}

No contexto histórico da humanidade, a deficiência foi marcada por diferentes momentos de exclusão, desde as sociedades ágrafas à modernidade (Costa-Renders, 2009). Dessa forma, a recusa de Pessoas com Deficiência (PcD) prevaleceu por séculos, sendo excluídas, segregadas e integradas, para só depois vir a serem incluídas como um ser social. Percebe-se assim o grande desafio que se configura a promoção do recém processo de inclusão para uma sociedade habituada a excluir.

A inclusão social e educacional tem se desenvolvido, nos últimos anos, como um movimento mundial em consequência às desigualdades sociais e preconceitos históricos sofridos pelos deficientes (Miranda, 2019). E, mesmo a 
educação sendo um direito de todos, a inclusão escolar tem se tornado um grande desafio para o sistema educacional, na busca da universalização e unificação da educação (Saviani, 2011). Dessa forma, cabe ao Estado, a missão de promover estratégias de superação dos obstáculos ainda presentes no processo de inclusão nos âmbitos escolar e social (Matiskei, 2004).

Nesse contexto, a presente pesquisa buscou conhecer a perspectiva da educação inclusiva na rede estadual urbana do município de Breves -PA. Assim, em quatro (04) escolas da rede estadual foram aplicados questionários a equipe pedagógica, às escolas: A) Escola Estadual de Ensino Médio Professora Maria Câmara Paes (MCP); B) Escola Estadual de Ensino Médio Professora Maria Elizete Fona Nunes; C) Escola Estadual de Ensino Médio Professor Gerson Peres e D) Escola Estadual de Ensino Fundamental e Médio Santo Agostinho. Segue, portanto, os principais resultados desse diagnóstico.

\subsection{Perfil Histórico Escolar}

Esse perfil buscou analisar aspectos históricos das escolas como ano de fundação, origem do nome e quando iniciou seus trabalhos com Ensino Médio (Tabela 1). Investigou-se a existência de documentação que registrem a trajetória desses espaços.

Tabela 1: Diagnóstico histórico das escolas da rede estadual de Breves.

\begin{tabular}{ccc}
\hline HISTÓRICO DAS ESCOLAS \\
$\begin{array}{c}\text { Escola Professora } \\
\text { Maria Câmara Paes }\end{array}$ & $\begin{array}{c}\text { Surgiu no ano de 1998 e seu nome homenageia uma professora da época. Suas aulas já } \\
\text { iniciaram no nível médio. Existem históricos que comprovam o surgimento da escola nesse } \\
\text { período, assim como alguns professores que ainda trabalham na escola. }\end{array}$ \\
\hline Escola Santo Agostinho & $\begin{array}{c}\text { O ensino médio iniciou no ano de 2008, seu nome é em decorrência Congregação das } \\
\text { Agostinianas Missionárias. Existem normativas que comprovam o surgimento da escola nesse } \\
\text { período, além de professores fundadores ainda ativos. }\end{array}$ \\
\hline $\begin{array}{c}\text { Escola Gerson Peres } \\
\text { Escola Elizete Fona } \\
\text { Nunes }\end{array}$ & $\begin{array}{c}\text { Em 2005 surgiu a escola, que homenageia o deputado federal Gerson Peres. Iniciou suas aulas } \\
\text { ján o ensino médio. Como não há documentos sobre sua origem, relatos de professores } \\
\text { ainda ativos e que trabalhavam na época, além de registros fotográficos, comprovam o } \\
\text { surgimento da escola nesse período. }\end{array}$ \\
\hline $\begin{array}{c}\text { Surgiu no ano de 2000, homenageando uma professora com seu nome. Suas aulas também } \\
\text { foram iniciadas com nível médio. Essa escola é a única com não possui documentos que } \\
\text { comprovam sua origem, entretanto, professores da época, ainda ativos, retratam sua história. }\end{array}$ \\
\hline
\end{tabular}

Fonte: Autores (2020).

Conclui-se que as escolas de ensino médio na cidade de Breves surgiram após os anos 90, sendo a mais antiga o Elizete Fona Nunes e a mais nova rede de ensino Médio o Santo Agostinho, seus nomes refletem homenagens. Todas as escolas têm professores que trabalham desde o seu surgimento, que junto com seus documentos históricos, possibilita a preservação de suas origens.

\subsection{Perfil Acadêmico Inclusivo da Escola}

A inclusão escolar para ser efetivada, precisa estar presente em documentos institucionais, fundamentando as práticas docentes, onde garante Atendimento Educacional Especializado (AEE) e outros direitos. Assim, buscou-se verificar aspectos inclusivos presentes nos Projeto-Político-Pedagógico (PPP) das escolas (Tabela 2). 
Tabela 2: Diagnóstico sobre a inclusão institucional das escolas.

\section{INCLUSÃO ACADÊMICA INSTITUCIONAL}

\begin{tabular}{cl}
\hline $\begin{array}{c}\text { Escola Professora } \\
\text { Maria Câmara Paes }\end{array}$ & $\begin{array}{l}\text { O Projeto-Político-Pedagógico (PPP) tem uma abordagem inclusiva nos objetivos e nas } \\
\text { diretrizes pedagógicas, mas seu PPC não apresenta disciplina inclusiva. A escola, possui } \\
\text { professores PcD e em preocupação com inclusão, já promoveu um curso de formação em libras } \\
\text { para servidores e alunos. }\end{array}$ \\
\hline $\begin{array}{c}\text { Escola Santo } \\
\text { Agostinho }\end{array}$ & $\begin{array}{l}\text { O Projeto-Político-Pedagógico (PPP) apresenta inclusão no plano de ação, diretrizes } \\
\text { pedagógicas e identificação de estruturas, mas o PPC não apresenta uma disciplina inclusiva. } \\
\text { Entretanto, a escola nunca recebeu nenhuma formação sobre educação especial ou inclusiva. }\end{array}$ \\
\hline Escola Gerson Peres & $\begin{array}{l}\text { O Projeto-Político-Pedagógico (PPP) possui uma perspectiva inclusiva em seu plano de ação e } \\
\text { diretrizes pedagógicas. O PPC não apresenta uma disciplina inclusiva, mas a escola possui } \\
\text { professores PcD. Quanto a formações inclusivas, não é uma realidade nesta escola. }\end{array}$ \\
\hline $\begin{array}{c}\text { Escola Elizete Fona } \\
\text { Nunes }\end{array}$ & $\begin{array}{l}\text { O Projeto-Político-Pedagógico (PPP) contempla em sua missão, visão, plano de ação e } \\
\text { diretrizes pedagógicas um contexto inclusivo, mas seu PPC também não apresenta disciplinas } \\
\text { especiais para seus alunos. A escola não possui professor de educação especial e não recebeu } \\
\text { formação na área. }\end{array}$ \\
\hline
\end{tabular}

Fonte: Autores (2020).

O Projeto-Político-Pedagógico (PPP) de todas as escolas apresentam aspectos inclusivos em algumas de suas sessões, mas não ofertam disciplinas no PPC, o que poderia proporcionar uma formação inclusiva para seus alunos, trazendo benefícios educacionais e sociais (Hehir et. al., 2016). Como aspectos inclusivos, algumas escolas possuem servidores especiais, uma atitude que promove respeito à diversidade, pois, numa "escola inclusiva a diversidade é valorizada em detrimento da homogeneidade" (Glat \& Fernandes, 2015 p. 04). Mesmo diante dessas características, a formação de servidores é insuficiente ou inexistente, pois apenas uma escola promoveu alguma capacitação. As escolas precisam promover formação continuada para toda equipe, em especial aos professores, garantindo uma infraestrutura física e pedagógica para execução deste processo, que implica numa nova abordagem didática.

\subsection{Perfil Acadêmico de Alunos com Deficiência}

O Atendimento Educacional Especializado (AEE) foi um direito garantido em 2008 pela Política Nacional de Educação Especial na Perspectiva da Educação Inclusiva. A política garante a participação e aprendizagem desse público nas escolas regulares, através de atividades que analisem as necessidades específicas e busquem eliminar barreiras (Brasil, 2008). Nesse contexto, o elo entre professores especializados e os estudantes deficientes é estabelecido pelo do AEE, através de sua atuação e com recursos adequados (Neves et al., 2019), o que reforça a importância desse serviço educacional em escolas, que foi verificado conforme demonstrado na Tabela 3. 
Tabela 3: Diagnóstico sobre alunos especiais e AEE nas escolas da rede estadual de Breves.

\section{ALUNOS PCD e AEE}

\begin{tabular}{|c|c|}
\hline \multicolumn{2}{|r|}{ ALUNOS PcD e AEE } \\
\hline $\begin{array}{l}\text { Escola Professora } \\
\text { Maria Câmara Paes }\end{array}$ & $\begin{array}{l}\text { Seus alunos PcD possuem acompanhamento por professor itinerante de AEE, além de serem } \\
\text { assistidos por outras instituições especializadas. Nunca houve evasão de alunos especiais } \\
\text { desde o início de seu atendimento, em 2009. Ao longo dos últimos } 5 \text { anos a escola atendeu } \\
\text { alunos com transtorno mental (psicose), alteração genética (Síndrome de Down), transtorno } \\
\text { do espectro do autismo, deficiências físicas, surdo-mudo, cego e baixa visão. No ano de } \\
\text { 2020, a escola possui } 10 \text { alunos PcD matriculados, todos atendidos por AEE. }\end{array}$ \\
\hline $\begin{array}{c}\text { Escola Santo } \\
\text { Agostinho }\end{array}$ & $\begin{array}{l}\text { Com atendimento a alunos especiais desde } 2008 \text {, atualmente a escola atende } 02 \text { alunos PcD } \\
\text { matriculados, com acompanhamento de professor especializado (AEE). Nos últimos } 5 \text { anos } \\
\text { atendeu } 06 \text { alunos, com deficiência física, transtorno do espectro do autismo, surdo-mudo e } \\
\text { baixa visão, nunca houve evasão durante esse período. }\end{array}$ \\
\hline Escola Gerson Peres & $\begin{array}{l}\text { Em 2020, a escola possui } 13 \text { alunos PcD matriculados, com acompanhamento AEE de um } \\
\text { professor itinerante, mas seu atendimento iniciou em } 2011 \text {. Ao longo dos últimos } 5 \text { anos, a } \\
\text { escola recebeu } 18 \text { alunos com diferentes deficiências e/ou transtornos, tais como deficiência } \\
\text { física, transtorno do espectro do autismo, surdo-mudo e baixa visão, nunca houve evasão } \\
\text { durante esse período. }\end{array}$ \\
\hline $\begin{array}{c}\text { Escola Elizete Fona } \\
\text { Nunes }\end{array}$ & $\begin{array}{l}\text { Com os } 04 \text { anos de atendimento a alunos especiais, iniciado em 2016, a escola acompanhou } \\
03 \text { alunos com deficiências físicas e sem índices de evasão. Nas matrículas de 2020, não } \\
\text { consta alunos PcD e, por consequência, a escola não possui professor de AEE. }\end{array}$ \\
\hline
\end{tabular}

Fonte: Autores (2020).

O atendimento aos alunos PcD nessas escolas iniciou entre 2008 e 2011, apenas a escola Elizete Fona Nunes, com um atendimento mais recente, no ano de 2016. No total, 53 alunos PcD foram atendidos ao longo dos últimos 5 anos, e desses não houve nenhuma evasão. Para o ano letivo de 2020, 25 alunos PcD estão matriculados na rede estadual urbana do município de Breves. Quanto ao acompanhamento desses alunos, apenas a escola Elizete Fona Nunes não possui AEE, enquanto as demais, mesmo que de forma itinerante, promovem essa inclusão.

\subsection{Perfil de Acessibilidade Escolar}

A inclusão escolar, para ser efetivada, precisa romper barreiras para possibilitar a participação incondicional de todos os alunos (Brasil, 2008). Entre essas barreiras está a acessibilidade, que conforme a Lei Brasileira de Inclusão de Pessoas com Deficiência (Brasil, 2015), se tornou um direito às pessoas com deficiência ou mobilidade reduzida para uma vida cidadã independente. Mas, para que esse direito seja garantido, é preciso condições de acesso e participação em todos os espaços (Kraemer \& Thoma, 2018). Assim, segue uma breve análise da acessibilidade de escolas estaduais que atendem alunos especiais em Breves (Tabela 4). 
Tabela 4: Diagnóstico sobre acessibilidade das escolas estaduais de Breves.

\begin{tabular}{cl}
\hline & ACESSIBILIDADE ESCOLAR \\
\hline $\begin{array}{c}\text { Escola Professora } \\
\text { Maria Câmara Paes }\end{array}$ & $\begin{array}{l}\text { A escola possui rampas de acesso e um auditório acessível aos alunos. Possui uma sala AEE e } \\
\text { equipamentos de tecnologia assistiva, tais como scanner auditivo e impressora de braile. }\end{array}$ \\
\hline $\begin{array}{c}\text { Escola Santo } \\
\text { Agostinho }\end{array}$ & $\begin{array}{l}\text { A escola possui espaços acessíveis, sendo eles a rampa de acesso ao banheiro, a entrada da } \\
\text { escola e a área da escola. A escola possui uma sala AEE, porém funciona somente para o } \\
\text { ensino fundamental. }\end{array}$ \\
\hline $\begin{array}{c}\text { Todos os espaços da escola são acessíveis, possuindo corrimão, rampa, banheiro adaptado, } \\
\text { placas de orientação e piso tátil. A escola também possui uma sala para atendimento } \\
\text { educacional especializado. }\end{array}$ \\
\hline $\begin{array}{l}\text { Escola Elizete Fona } \\
\text { Nunes }\end{array}$ & A escola não possui qualquer tipo de acessibilidade. \\
\hline
\end{tabular}

Fonte: Autores (2020).

De certo modo, as escolas possuem acessibilidade e espaços coletivos para alunos PcD e com salas especializadas para AEE. Contudo, apenas a Escola Maria Câmara Paes oferece tecnologia assistiva. Sendo este um mecanismo para a autonomia e independência de pessoas com deficiências, promovendo, sobretudo, direitos humanos (Baldassin, et. al., 2008). A exceção se aplica a Escola Elizete Fona, que não possui qualquer tipo de acessibilidade para alunos especiais. Destaca-se então, a necessidade de uma preparação efetivas das escolas para atender aos alunos especiais, requerendo fortes investimentos do Estado, sobretudo na região norte, com formações, estímulos a pesquisas diagnósticas para identificar as fragilidades e potencialidades e garantir a qualidade na promoção da educação inclusiva (Penha, et. al, 2020).

Dessa forma, reflete-se sobre a importância na existência de fato de uma educação de direito, que garanta o acesso, o convívio e a cidadania. Pois a escola é o espaço de proteção e promoção de equidade social, que além de instruções educativas, abrange princípios de acessibilidade, adaptabilidade e disponibilidade (Santos, 2019). Essa é a função de uma educação inclusiva, fazer com que os alunos tenham os mesmos direitos, com um ambiente que permita o convívio de todos (Figueira, 2011). Além disto, é importante conhecer as percepções dos docentes quanto ao processo e a implementação de fato de uma educação inclusiva, pois esta, tem sido um grande desafio para os professores, pois muitos têm um contato inicial repleto de incertezas (Cenci et. al., 2016), muitas por não terem formação e/ou experiência na área.

\section{Conclusão}

Conclui-se, portanto, a necessidade de uma acessibilidade pedagógica e estrutural nas escolas, onde faça-se com que a inclusão não se limite à atendimentos educacionais especializados e espaços acessíveis, mas uma abordagem que promova uma inclusão holística, de documentos institucionais a práticas pedagógicas e sociais. É importante que o Estado possa promover capacitações à comunidade acadêmica, a fim de possibilitar que suas dificuldades sejam enfrentadas, suas práticas exitosas potencializadas, para que a escola possa sua totalidade incluir toda sociedade.

Deste modo, é proposto que haja a ampliação dessa pesquisa em futuros trabalhos para a verificação das estratégias, ações e desafios na promoção de uma educação inclusiva nas escolas do Marajó. Se faz necessário constar as dificuldades encontradas pela gestão e docentes quanto à implantação de uma escola mais inclusiva. Em suma, conhecer o cenário pedagógico da inclusão em Breves poderá fomentar parcerias, na busca da implementação de um ensino mais inclusivo no IFPA Campus Breves, além de promover a discussão sobre a importância da Educação Inclusiva, na perspectiva de perceber e valorizar a diversidade social e educacional. 


\section{Agradecimentos}

À PROPPG do IFPA pela concessão de bolsa PIBIC a terceira autora, aluna bolsista do projeto de pesquisa de mesmo título do artigo, aprovado no Edital nº 03/2019 PROPPG-IFPA-CNPq. Estendemos o agradecimento às escolas urbanas da rede estadual de Breves-PA, pelo aceite do convite e disponibilidade dos funcionários em contribuir com a pesquisa.

\section{Referências}

Baldassin, V., Lorenzo, C. \& Shimizu, H. E. (2018). Tecnologia assistiva e qualidade de vida na tetraplegia: abordagem bioética. Rev. Bioét. 26 10.1590/198380422018264276

Brasil. (2015). Lei Brasileira de Inclusão da Pessoa com Deficiência (13.146/2015). 2015. http://portal.mec.gov.br/arquivos/pdf/politicaeducespecial.pdf.

Bruno, M. M. G., \& Nascimento, R. A. L. (2019). Política de Acessibilidade: o que dizem as pessoas com deficiência visual. Educação \& Realidade, 44, e84848. http://www.planalto.gov.br/ccivil_03/_ato2015-2018/2015/lei/113146.html.

Censi, A., Bôas, D. F. V. \& Damiani, M. F. (2016). The challenge of inclusive education in a Brazilian School: teachers' concerns regarding inclusion. Research, Society and Development, 2, 94-106.

Costa, V. E. S. (2006). Educação, inclusão e políticas públicas: a educação especial no município de Marabá-Pará. Dissertação (Mestrado em Educação) Universidade Federal do Pará, Centro de Educação, Programa de Pós-Graduação em Educação, Belém.

Costa-Renders, E. C. (2009). Educação e Espiritualidade: pessoas com deficiência, sua invisibilidade e emergência. Paulus.

Figueira, E. (2011). O que é educação inclusiva? Brasiliense.

Garcia, D. I. B., \&Favaro, N. A. L. G. (2020). Special Education: public policies in Brazil and current trends. Research,Society and Development.9 (7):1-29. e184973894.

Glat, R. \& Fernandes, E. M. (2005). Da educação segregada à educação inclusiva: uma breve reflexão sobre os paradigmas educacionais no contexto da educação especial brasileira. Revista Inclusão $\mathrm{n}^{\circ} 1$, MEC/ SEESP.

Hehir, T. et. al. (2016). Os benefícios da educação inclusiva para estudantes com e sem deficiência. Alana: Abt Associates.

Kraemer, G. M. \& Thoma, A. S. (2018). Acessibilidade como Condição para a Inclusão Escolar. Psicologia: Ciência e Profissão. $38,554-563$.

Matiskei, A. C. R. M. (2004). Políticas públicas de inclusão educacional: desafios e perspectivas. Educar em Revista, $20,185-202$.

Melo, C. H. (2015). A história da educação inclusiva no município de Breves. Trabalho de conclusão de curso / lato senso - FAM - Breves.

Miranda, F. D. (2019). Aspectos Históricos da Educação Inclusiva no Brasil. Pesquisa e Prática em Educação Inclusiva, 2.

Neves, L. R., Rahme, M. M. F. \& Ferreira, C. M. R. J. (2019). Política de Educação Especial e os Desafios de uma Perspectiva Inclusiva. Educação \& Realidade, 44, e84853.

Penha, A. C. F. M., Fecury, A. A., Pascoal, R. M., et. al. (2020) Matrículas da Educação Especial na Educação Profissional Técnica de Nível Médio noEstado doAmapá (2015-2018). Research, Society and Development, 9, e881974867.

PME, Breves/PA. (2015). Lei nº 2.388/2015 - Plano Municipal de Educação, Breves

Romão-Torres, Essia de Paula. (2020). Mapa de Localização de Breves na Mesorregião do Marajó. No prole.

Santos, É. (2019). A educação como direito social e a escola como espaço protetivo de direitos: uma análise à luz da legislação educacional brasileira. Educ. Pesqui. 45, e184961.

Saviani, D. (2011). Pedagogia histórico-crítica: primeiras aproximações. (8a ed.), Autores Associados.

Saviani, D. (2020). Política Nacional de Educação Especial na perspectiva da Educação Inclusiva. 